\title{
Correction to: Hermeneutic Inquiry for Digital Games Research
}

\section{Theresa Jean Tanenbaum ${ }^{1}$}

Published online: 25 April 2020

(c) Springer Science+Business Media, LLC, part of Springer Nature 2020

\section{Correction to: Comput Game J (2015) 4:59-80 https://doi.org/10.1007/s40869-015-0005-9}

Since the publication of this article [Tanenbaum J. Hermeneutic Inquiry for Digital Games Research, Comput Game J (2015) 4:59-80, https://doi.org/10.1007/s4086 9-015-0005-9], the author Joshua Tanenbaum has now become known by the new legal name Theresa Jean Tanenbaum.

The original article can be found online at https://doi.org/10.1007/s40869-015-0005-9.

Theresa Jean Tanenbaum tess.tanen@gmail.com

1 Department of Informatics, Donald Bren School of Information and Computer Sciences, University of California, Irvine, CA 92617, USA 